\title{
Reduced Expression of the Inhibitory Genes for Fas-Mediated Apoptosis in Silicosis Patients
}

\author{
Takemi Otsuki $^{1}$, Akiko Tomokuni ${ }^{1}$, Haruko SAKAguchi ${ }^{1}$, Fuminori Hrodoh ${ }^{1}$, \\ Masayasu Kusaka ${ }^{2}$ and Ayako UEkI ${ }^{1}$ \\ 'Department of Hygiene, Kawasaki Medical School, \\ 'Department of Internal Medicine, Kusaka Hospital
}

\begin{abstract}
Reduced Expression of the Inhibitory Genes for Fas-Mediated Apoptosis in Silicosis Patients: Takemi OTsuki, et al. Department of Hygiene, Kawasaki Medical School-Silicosis cases are characterized not only by respiratory disorders but by various immunological abnormalities, but the cellular biological effects of silica compounds on human lymphocytes have not been well investigated. Our previous studies revealed high serum soluble Fas (sFas) levels in silicosis patients without any clinical symptoms of autoimmune disease and the dominant expression of sFas mRNA in peripheral blood mononuclear cells (PBMC) derived from these patients. These observations indicate that dysregulation of the Fas gene may play an important role in the pathogenesis of the immunological abnormalities found in silicosis patients. Recently several molecules with inhibitory or regulatory effects on Fas-mediated apoptosis have been identified and their cellular biological roles investigated. We examined the mRNA expression of inhibitory genes (TOSO, sentrin, and CFLIP), regulatory genes (CPAN and DFF45), and caspases (caspase $-1,-3$, and -8 ) in PBMC derived from silicosis patients. The results showed a reduced expression of sentrin, CFLIP and DFF45 and an overexpression of caspase-1. Nevertheless, considering the remarkable dominant expression of sFas in silicosis, the dysregulation of inhibitory genes and caspase-1 may be evidence of a Fas-mediated apoptotic pathway activated via the remaining membrane Fas molecules in the PBMC of silicosis patients.

(J Occup Health 2000; 42: 163-168)
\end{abstract}

Key words: Autoimmunity, Fas-mediated apoptosis, Inhibitory gene, mRNA, Silicosis

Received Dec 26, 1999; Accepted March 8, 2000

Correspondence to: T. Otsuki, Deparment of Hyicne, Kawasaki Medical School 577 Matsushima. Kurashiki, Okaryama 701-0192. Sapan
Cases of silicosis are characterized not only by respiratory disorders but also by various immunological abnormalities such as hypergammaglobulinemia, and the appearance of autoantibodies or complications of autoimmune disease, typically, progressive systemic sclerosis (PSS) and systemic lupus crythematosus (SLE) ${ }^{1-71}$, but the cellular biological effects of silica compounds on human lymphocytes have been little investigated.

We have been studying the immunological aspects of silicosis focusing on Fas-mediated apoptosis ${ }^{8-13}$, because of the abnormalities in Fas and related molecules which have been reported in human idiopathic autoimmune diseases such as SLE and rheumatoid arthritis ${ }^{1+-17}$. We have demonstrated high serum soluble Fas (sFas) levels in patients with silicosis without any clinical symptoms of autoimmune disease, including sclerotic skin, Raynaud's phenomenon, facial erythema or arthralgia. ${ }^{8}$ ?! and dominant expression of $\mathrm{sFas}$ mRNA in peripheral blood mononuclear cells (PBMC) derived from these patients ${ }^{10.11}$. These observations indicate that dysregulation of the Fas gene may play an important role in the pathogenesis of the immunological abnormalities found in silicosis patients.

To date several molecules with inhibitory or regulatory effects on Fas-mediated apoptosis have been identified and their cellular biological roles investigated. The TOSO $^{\mid 8,}$, sentrin ${ }^{19)}$ and cFLIP ${ }^{191}$ (also called CASPER, IFlice, Flame-1, CASH, CLARP, NMRIT or usurpin ${ }^{\mid(1)}$ ) genes have been reported to cause inhibition by binding with Fas or caspase-8 (Flice), or by competing with FADD. Activation of caspase- 8 subsequently induces the activation of other caspases, such as caspase-4 (ICH2), caspase-1 (ICE), caspase-3 (Yama/CPP32), and caspase7 (Mch3) $)^{20-23}$. In addition, DNA fragmentation during apoptosis is mediated by a heterodimeric protein complex composed of DFF45/ICAD ${ }^{241}$ and DFF40/CAD/CPAN 25 . These proteins are located downstream of caspase- 3 to trigger DNA fragmentation and change the chromatin 
structure, but it has also been reported that DFF45 functions as an inhibitory factor in caspase-sensitive nuclease. In any case, DFF45 and CPAN possess regulatory activity for DNA fragmentation induced by activation of caspases ${ }^{26-28)}$.

In this study, to address the selection of peripheral lymphocytes via an apoptotic pathway, we examined the mRNA expression of inhibitory genes (TOSO, sentrin. and cFLIP), regulatory genes (CPAN and DFF45), and caspases (caspase- $1,-3$, and -8 ) in PBMC derived from silicosis patients.

\section{Materials and Methods}

\section{Cases studied}

Twelve patients with silicosis (average age, $68.2 \pm 1.3$ yr) without any clinical symptoms of autoimmune disease, such as sclerotic skin, Raynoud's phenomenon, facial erythema or arthlargia or any malignant tumors, and eight age-matched healthy volunteers (average age; $64 \pm 7 \mathrm{yr}$ ) were the subjects of this study. All the patients and healthy volunteers were Japanese and gave informed consent according to the guidelines of the Institutional Review Board of Kawasaki Medical School and Kusaka Hospital.

\section{RNA extraction and CDNA synthesis}

PBMC were isolated from $10 \mathrm{~m} l$ of heparinized blood in each case by the Ficoll-Hypaque density centrifugation method (Lymphoprep ${ }^{\mathrm{TM}}$, Nycomed Pahrma As, Oslo. Norway). Total cellular RNA was extracted with a TRIzol ${ }^{\mathrm{TM}}$ reagent (GIBCO BRL Life Technologies, Gaithersburg, MD, USA), according to the manufacturer's instructions. One microgram of total RNA and oligo(dT) ${ }_{1 \times}$ primer (final concentration; $1 \mu \mathrm{M}$ ) in $12.5 \mu l$ of diethyl pirocarbonate (DEPC)-treated $\mathrm{H}_{2} \mathrm{O}$ was heated to $70^{\circ} \mathrm{C}$ for $2 \mathrm{~min}$ then cooled on ice for $1 \mathrm{~min}$. cDNA synthesis was started with 200 units of recombinant MMLV
(Moloney-Murine Leukemia Virus) reverse transcriptase (Clonthech Lab. Inc., Palo Alto, CA, USA) under conditions recommended by the manufacturer, and the reaction was allowed to proceed at $42^{\circ} \mathrm{C}$ for $60 \mathrm{~min}$. The reaction was terminated by heating at $94^{\circ} \mathrm{C}$ for $5 \mathrm{~min}$ and then the mixture was diluted to a final volume of $100 \mu l$ by adding $80 \mu l$ of DEPC-treated $\mathrm{H}_{2} \mathrm{O}$.

\section{Multiplex reverse-transcriptase-polymerase chain reaction (MP-RT-PCR)}

MP-RT-PCR was used to examine the mRNA expression level for the inhibitory, regulatory genes of the Fas-mediated apoptotic pathway and caspases in the PBMC of the silicosis patients and the volunteers. The primer sequences used in this study, the expected size of each RT-PCR amplicon, the annealing temperature and the RT-PCR cycles for each primer set are listed in the Table. To amplify $\beta$-actin, the housekeeping control gene and the targeted gene in a single reaction, MP-RT-PCR was carried out. The ratios of primer-sets in the targeted gene and $\beta$-actin are shown in the Table. These ratios and PCR cycles were determined to amplify both products logarithmically and in relatively similar amounts. Each MP-RT-PCR mixture contained $1 / 100$ of cDNA (equivalent to a cDNA amount from $10 \mathrm{ng}$ of initial total RNA), $200 \mathrm{nM}$ concentrations of each primer, $200 \mu \mathrm{M}$ of deoxynucleotide triphosphates, $10 \mathrm{mM}$ of Tris-HCL ( $\mathrm{pH} 8.8$ ), $1.5 \mathrm{mM}$ of $\mathrm{MgCl}_{2}, 50 \mathrm{mM}$ of $\mathrm{KCL}, 0.08 \%$ Nonident P40, and one unit of recombinant Thermus aquatics DNA polymerase (Sawady Technologies, Tokyo, Japan) in a final volume of $20 \mu \mathrm{l}$. After an initial denaturation for $4 \mathrm{~min}$ at $94^{\circ} \mathrm{C}, 27$ to 34 cycles of denaturation $\left(94^{\circ} \mathrm{C}\right.$ for $\left.15 \mathrm{sec}\right)$, annealing $\left(57\right.$ to $60^{\circ} \mathrm{C}$, as shown in the table, for $15 \mathrm{sec})$, and extension $\left(72^{\circ} \mathrm{C}\right.$ for $30 \mathrm{sec}$ ) were performed on a DNA thermal cycler (PC960G Microplate Gradient Thermal Cycler, Mortlake, Australia). The final extension time was $5 \mathrm{~min}$. After

Table. Sequence, anncaling temperature (Ta), mixed ratio with $\beta$-actin primer set, cycles, and expected size of each primer set used for multiplex RT-PCR to examine the relative expression level of each gene

\begin{tabular}{|c|c|c|c|c|c|}
\hline Gene & sequences of primers & $\mathrm{Ta}\left({ }^{\circ} \mathrm{C}\right)$ & $\begin{array}{c}\text { ratio } \\
\text { (gene: } \beta \text {-actin) }\end{array}$ & cycles & size $(b p)$ \\
\hline TOSO & F, $5^{\prime}$-acaacatctacagcgcetgc- $3^{\circ}, \mathrm{R}, 5^{\prime}$-cagctggtettcagagatgg-3' & 58 & $2: 0.5$ & 30 & 280 \\
\hline Sentrin & F, 5'-tgacggaagttactgcagec-3', R, 5'-catcttettectccattcce-3' & 57 & $2: 0.4$ & 30 & 387 \\
\hline cFLIP & F, 5'-aagaggtaagctgtctgtcgg- $3^{\prime}, \mathrm{R}, 5^{\prime}$-tccttgettatcttgcetcg-3' & 57 & $2: 0.4$ & 30 & 185 \\
\hline DFF45 & F, $5^{\prime}$-aaggcetglgacattctggc-3', R, 5'-tgataggaggatgatgctgg-3' & 57 & $2: 0.5$ & 30 & 294 \\
\hline CPAN & F, 5'-ascgtcagccagaacatcg-3', R. $5^{\circ}$-gceattgtactgcatggacc-3' & 60 & $2: 0.3$ & 30 & 240 \\
\hline Caspase-1 & F, 5'-aatggacaagtcaagccgc-3', R. 5'-tgctgtcagaggtcttgtgc-3' & 56 & $2: 0.75$ & 32 & 224 \\
\hline Caspase-3 & F, 5'-tcggtctggtacagatgtcg-3', R, 5'-catacaagaagtcggectce-3' & 60 & $2: 0.3$ & 34 & 398 \\
\hline Caspase- 8 & F, 5'-acagtgaagatctggcetcc-3', R, 5' -gcaggtlcatgtcatcatcc-3' & 57 & $2: 0.5$ & 27 & 375 \\
\hline$\beta$-actin & $\begin{array}{l}\text { F, 5'-tgacggggteacceacactgtgccatcta-3' } \\
\text { R, 5'-ctagaagcatttgcggtggacgatggaggg-3, }\end{array}$ & & & & 610 \\
\hline
\end{tabular}


visualization of the MP-RT-PCR products by $1.2 \%$ agarose gel stained with ethidium bromide, gel images were obtained with a FAS-II UV-image analyzer (Toyobo Co. Ltd., Tokyo, Japan), and the densities of the products were quantified with the Quantity One TM version 2.5 (PDI Inc.. Huntington Station, NY, USA). The relative expression level of each targeted gene in individual cases was calculated as the density of the product of that gene divided by that of the $\beta$-actin gene derived from the same MP-RT-PCR.

\section{Statistical analysis}

The relative expression level for each gene in the individuals with silicosis and the volunteers was statistically analyzed by the Mann-Whitney test.

\section{Results}

\section{$M P-R T-P C R$}

The MP-RT-PCR products obtained from each patient and healthy volunteer for all of the targeted genes are shown in Fig. 1. The products of the MP-RT-PCR for the sentrin and $\beta$-actin genes in the silicosis cases seem to reveal similar intensities for both genes, but in the healthy volunteers (HV) relatively larger amounts of sentrin products than $\beta$-actin products were found. These findings mean that the relative expression level of the sentrin gene may be lower in patients with silicosis than in healthy individuals. We then digitalized all products, as described in Materials and Methods, and performed a statistical analysis for each gene to find any significant differences between the patients with silicosis and the volunteers.

\section{Relative expression level of each gene studied}

The relative expression level of each gene in individual patients and volunteers was plotted and the averages for those subjects with and without silicosis (SIL) are shown in Fig. 2. Significant differences were detected in sentrin (SIL; $1.07 \pm 0.12$ (mean $\pm \mathrm{SD}$ ), HV; $2.07 \pm 0.47$, $\mathrm{p}=.0003$ ), cFLIP (SIL; $0.75 \pm 0.24, \mathrm{HV} ; 1.01 \pm 0.08$, $\mathrm{p}=.0069)$, DFF45 (SIL; $0.25 \pm 0.12, \mathrm{HV} ; 0.32 \pm 0.08$, $\mathrm{p}=.0143$ ), and caspase-1 (SIL; $0.79 \pm 0.15$. HV; $0.61 \pm$ $0.20, p=.0372$ ). The expression of the sentrin, cFLIP and DFF45 genes was reduced in cases of silicosis, but caspase-1 was significantly overexpressed.

\section{Discussion}

In this study we were able to detect a significant reduction in the expression level of genes possessing inhibitory effects for Fas-mediated apoptosis, such as sentrin and cFLIP, and significant overexpression of the caspase- 1 gene. In addition, reduced expression of the DFF45 gene was also observed. Since the removal of the DFF45 molecule from the CPAN/DFF45 complex induces DNA fragmentation ${ }^{2+-281}$, all of these results

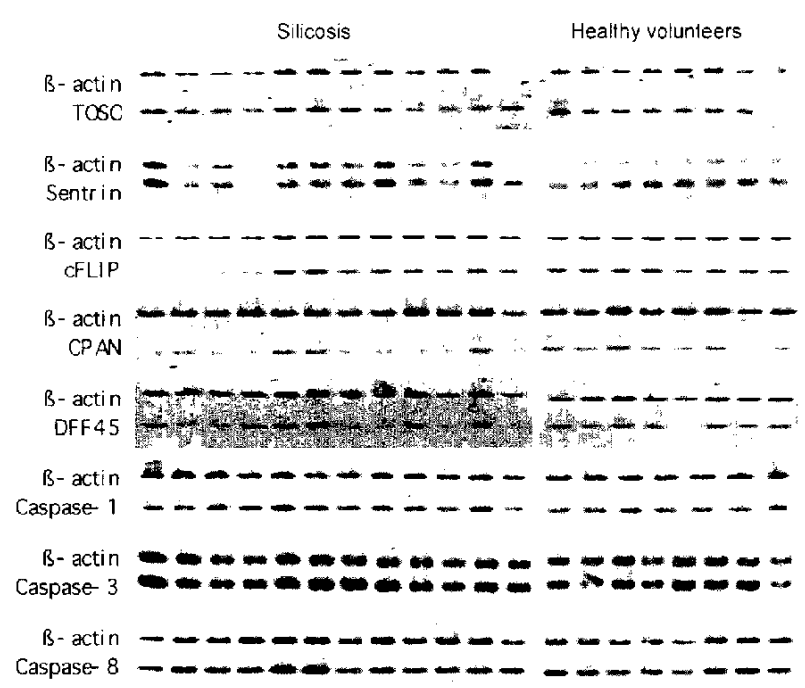

Fig. 1. MP-RT-PCR products of the inhibitory genes; TOSO, sentrin, and CFLIP, and regulatory genes; CPAN and DFF45, for the Fas-mediated apoptotic pathway and caspases; caspase- $1,-3$, and -8 in PBMC derived from the patients with silicosis and healthy volunteers. After visualization of the MP-RT-PCR products on $1.2 \%$ agarose gel stained with ethidium bromide, gel images were obtained in a FAS-II UV-image analyzer (TOYOBO Co. Ltd., Tokyo, Japan), and the densities of the products were quantified with Quantity One $\mathrm{TM}$ version 2.5 (PDI Inc., Huntington Station, NY, USA). The relative expression level of each targeted gene in individual cases was calculated as the density of the product of the gene divided by that of the $\beta$-actin gene derived from the same MP-RT-PCR.

indicate that Fas-mediated apoptosis in PBMC derived from silicosis patients is significantly activated. On the other hand, our previous investigations led us to conclude that the $\mathrm{T}$ lymphocytes in silicosis patients are resistant to apoptosis mediated by the Fas-related pathway ${ }^{\text {x-1.3. }}$. Moreover, these T cells may include self-recognizing clones, since our previous results demonstrated that silica compounds act as superantigens to human $\mathrm{T}$ cells ${ }^{29-3.3}$. It should be noted, however, that the membrane Fas expression in peripheral lymphocytes from these patients is not altered compared with healthy volunteers ${ }^{x . y}$.

These findings have led us to speculate that $T$ cells which possess membrane Fas on their surface are sensitive to Fas-mediated apoptosis. This hypothesis was also arrived at in our previous study which demonstrated that T lymphocytes in healthy volunteers were sensitive to stimulation-induced cell death caused by silica compounds in vitro ${ }^{34 !}$. Taken together, it seems possible that the T cells in patients with silicosis are of two types, one of which is resistant to apoptosis mediated by the Fas-related pathway. and the other which easily undergoes Fas-mediated apoptosis caused by exposure to silica. 


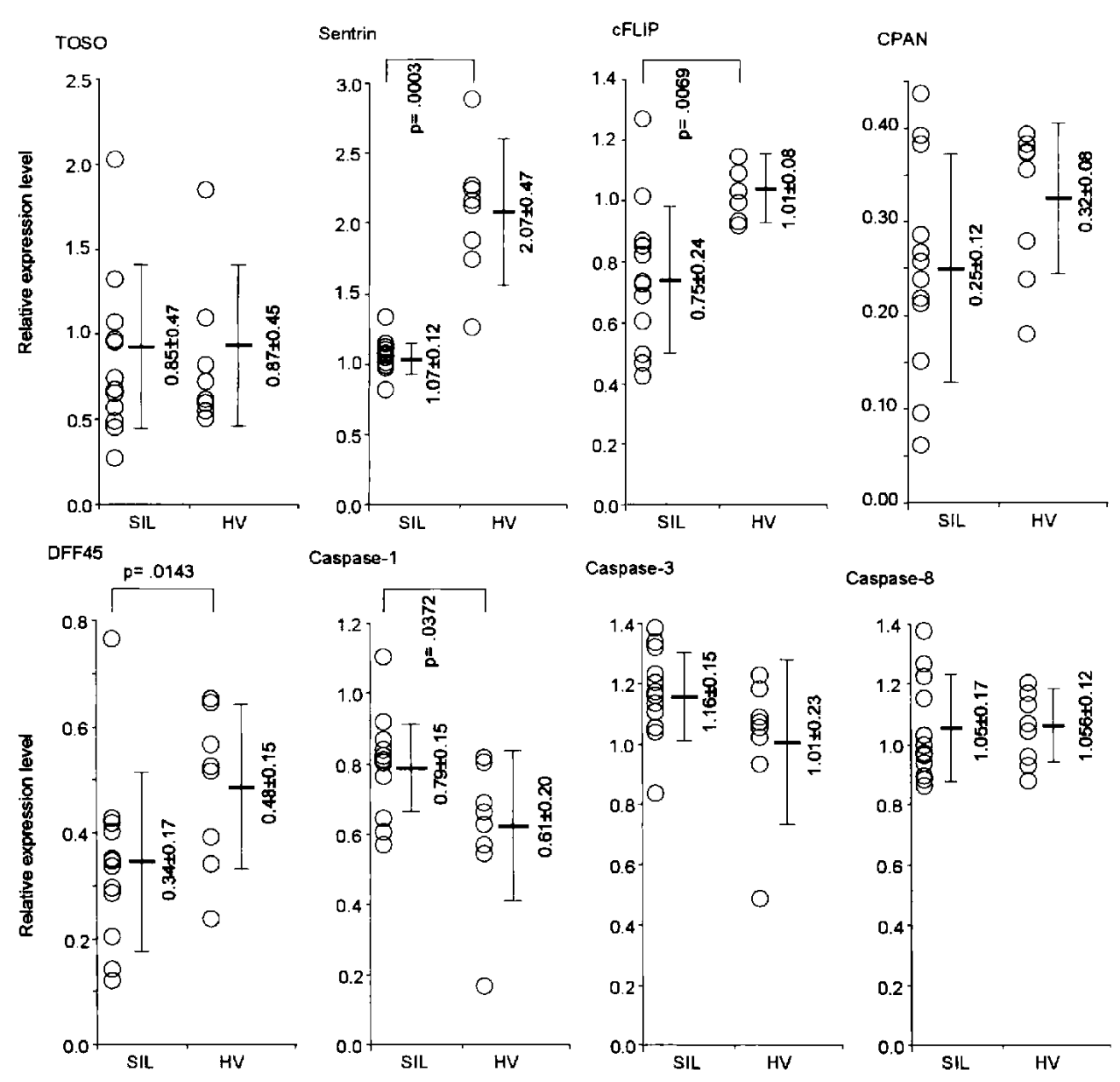

Fig. 2. The plotting of the relative expression level of each gene studied in the patients with silicosis (SIL) $(n=12)$ and healthy volunteers (HV) $(n=8)$. Significant differences were detected in sentrin (SIL; $1.07 \pm 0.12$ (mean $\pm \mathrm{SD}$ ). HV; $2.07 \pm 0.47, \mathrm{p}=.0003$ ), cFLIP (SIL; $0.75 \pm 0.24$, $\mathrm{HV} ; 1.01 \pm 0.08, \mathrm{p}=.0069$ ). DFF45 (SIL: $0.25 \pm 0.12$. HV; $0.32 \pm 0.08 . \mathrm{p}=.0 \mathrm{I} 43$ ), and caspase1 (SIL; $0.79 \pm 0.15, \mathrm{HV} ; 0.61 \pm 0.20, p=.0372$ ). The expression of sentrin, cFLIP, and DFF45 genes was reduced in the cases of silicosis. but caspase- 1 was significantly overexpressed. In addition. DFF45 was also relatively little expressed in those with silicosis.

Therefore, the former fraction of T cells may consist of long-surviving self-recognizing clones induced by chronic and recurrent occupational exposure to silica compounds and the latter fraction of $T$ cells, which are sensitive to silica-induced apoptosis like healthy $\mathrm{T}$ cells (schematically shown in Fig. 3), and may die and be recruited again and again. But the former fraction may survive longer and extend throughout the body to play an important role in immunological abnormalities in silicosis.

Although we have reported that parameters related to Fas-mediated apoptosis such as serum sFas levels and sFas message expression in PBMC should be the most useful for predicting the pre-clinical status of complicated autoimmune diseases in silicosis ${ }^{35}$. it is not yet clear whether the results of that study indicate immunological disorders in silicosis, or represent the degree of occupational exposure to silica compounds. Although little is known about the relation between the expression of inhibitory genes for Fas-mediated apoptosis and autoimmune diseases, recently Van Parijs et al. reported that activation-dependent downregulation of cFLIP renders mature lymphocytes sensitive to death receptormediated apoptosis and is required to maintain selftolerance ${ }^{3(6)}$. Two populations of lymphocytes in silicosis patients as shown in Fig. 3, may therefore have opposite functions in autoimmunity. Further investigation is required to elucidate the role of Fas-mediated apoptosis in silicosis to contribute to the prevention of immunological disorders found in those suffering from this occupational disease. 


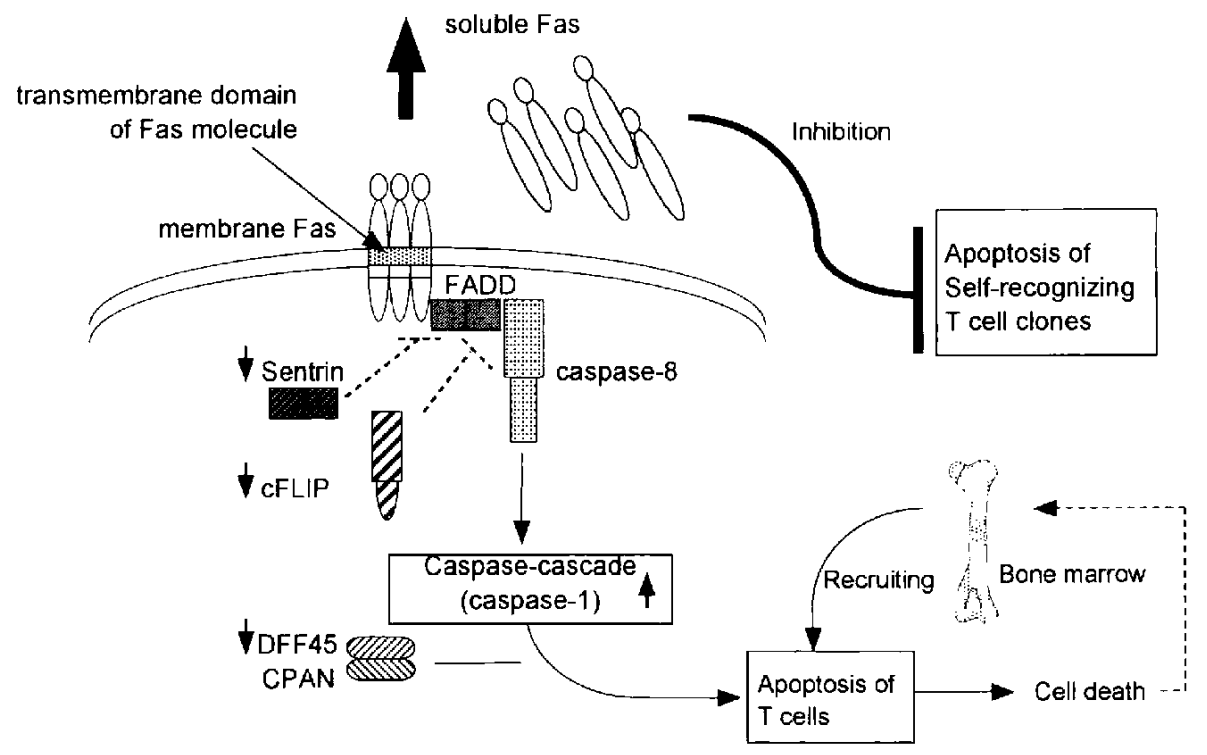

Fig. 3. Schematic model of dysregulation of the Fas-mediated apoplotic pathway in patients with silicosis.

\section{Conclusion}

In this study we found reduced expression of inhibitory genes for Fas-mediated apoptosis in PBMC derived from silicosis patients. These results and previous investigations indicating the existence of a lymphocyte fraction which is resistant to Fas-mediated apoptosis suggest the presence of two fractions of lymphocytes in silicosis patients. To prevent not only respiratory diseases but immunological disorders in silicosis patients, further study into the role of Fas-mediated apoptosis in these patients is required.

Acknowledgment: The authors thank Professor David $\mathrm{H}$. Waterbury for his editorial contribution, Professor Shoichi Kita, Department of Primary Health Care and Preventive Medicine, Kawasaki Medical School for assistance with collecting samples, and Ms. Yumika Isozaki for skilfu] technical assistance. This work was supported by the Japan Rheumatoid Diseases Research Foundation, Kawasaki Medical School Project Grant (8-105 and 9-105) and a Grant-in Aid for Scientific Research from the Japanese Ministry of Education, Science, Sports and Culture (1997).

\section{References}

1) Steenland K, Goldsmith DF. Silica exposure and autoimmune diseases. Am J Ind Med 1995; 28: 603608.

2) Sluis-Cremer GK, Hessel PA. Nizdo EH, Churchill AR, Zeiss EA. Silica, silicosis, and progressive systemic sclerosis. Br J Ind Med 1985; 42: 838-843.

3) Uber CL, McReynolds RA. Immunotoxicology of silica. Crit Rev Toxicol 1982; 10: 303-319.

4) Koeger AC, Lang T, Alcaix D, et al. Silica-associated connective tissue disease. A study of 24 cases. Medicine (Baltimore) 1995: 74: 221-237.

5) Haustein UF, Anderegg U. Silica induced sclerodermaclinical and experimental aspects. J Rheumatol 1998; 25: 917-926.

6) Haustein UF. Silica-induced lupus erythematosus. Acta Derm Venereol 1998; 78: 73-74.

7) Sanchez-Roman J, Wichmann I, Salaberri J, Varela JM, Nunez-Roldan A. Multiple clinical and biological autoimmune manifestations in 50 workers after occupational exposure to silica. Ann Rheum Dis 1993; 52: 534-538.

8) Tomokuni A, Aikoh T, Matsuki T, et al. Elevated soluble Fas/APO-1(CD95) levels in silicosis patients without clinical symptoms of autoimmune diseases or malignant tumours. Clin Exp Immunol 1997; 110: 303309.

9) Tomokuni A, Aikoh T, Matsuki T, et al. Elevated soluble Fas levels in patients with silicosis. In: Chiyotani K, Hosoda Y, Aizawa Y, eds. Advances in the Prevention of Occupational Respiratory Diseases. Amsterdam: Elsevier Science, 1998; 931-936.

10) Otsuki T, Sakaguchi H, Tomokuni A, et al. Soluble Fas mRNA is dominantly expressed in cases with silicosis. Immunol 1998; 94: 258-262.

11) Otsuki T, Tomokuni A. Sakaguchi H, et al. Soluble Fas message is dominantly expressed in cases with silicosis. In: Chiyotani K, Hosoda Y, Aizawa Y eds. Advances in the Prevention of Occupational Respiratory Diseases. Amsterdam: Elsevier Science, 1998: 896-900.

12) Tomokuni A, Otsuki T, Isozaki Y, et al. Serum levels of soluble Fas ligand in patients with silicosis. Clin Exp Immunol 1999; 118: 44 I-444.

13) Otsuki T, Tomokuni A, Sakaguchi H, et al. Over- 
expression of the decoy receptor 3 (DcR3) gene in peripheral blood mononuclear cells (PBMC) derived from silicosis patients. Clin Exp Immunol 2000; 119 : 323-327.

14) Tokano Y, Miyake S, Kayagaki N, et al. Soluble Fas molecule in the serum of patients with systemic lupus erythematosus. J Clin Immunol 1996; 16: 261-265.

15) Jodo S, Kobayashi S, Kayagaki N, et al. Serum levels of soluble Fas/APO-1 (CD95) and its molecular structure in patients with systemic lupus erythematosus (SLE) and other autoimmune diseases. Clin Exp Immunol 1997; 107: 89-95.

16) Nozawa $K$, Kayagaki N, Tokano $Y$, Yagita $H$, Okumura K, Hasimoto H. Soluble Fas (APO-1, CD95) and soluble Fas ligand in rheumatic diseases. Arthritis Rheum 1997; 40: 1126-1129.

17) Sakata K, Sakata A, Vela-Roch N, et al. Fas (CD95)transduced signal preferentially stimulates lupus peripheral T Iymphocytes. Eur J Immunol 1998; 28: 2648-2660.

18) Hitoshi Y, Lorens I, Kitada SI, et al. Toso, a cell surface, specific regulator of Fas-induced apoptosis in T cells. Immunity 1998; 8: 461-471.

19) Tschopp J, Irmler M, Thome M. Inhibition of Fas death signals by FLIPs. Curr Opin Immunol 1998; 10: 552558.

20) Thornberry NA. Caspases: key mediators of apoptosis. Chem Biol 1998; 5: R97-103.

21) Thornberry NA, Lazebnik Y. Caspases: enemies within. Science 1998; 281, 1312.

22) Harvey NL, Kumar $S$. The role of caspases in apoptosis. Adv Biochem Eng Biotechnol 1998; 62; 107-128.

23) Singh A, Ni J, Aggarwal BB. Death domain receptors and their role in cell demise. J. Interferon Cytokine Res 1998; 18: 439-450.

24) Liu $X$, Zou $H$, Slaughter $C$, Wang $X$. DFF, a heterodimeric protein that functions downstream of caspase- 3 to trigger DNA fragmentation during apoptosis. Cell 1997; 89: 175-184.

25) Halenbeck R, MacDonald H, Roulston A, Chen TT, Conroy L, Williams LT. CPAN, a human nuclease regulated by the caspase-sensitive inhibitor DFF45.
Curr Biol 1998; 8: 537-540.

26) Inohara $\mathrm{N}$, Koseki $\mathrm{T}$, Chen $\mathrm{S}$, Wu X, Nunez G. CIDE, a novel family of cell death activators with homology to the $45 \mathrm{kDa}$ subunit of the DNA fragmentation factor. EMBO J 1998; 17: 2526-2533.

27) Mitamura S, Ikawa H, Mizuno N, Kaziro Y, Itoh $H$. Cytosolic nuclease activated by caspase- 3 and inhibited by DFF-45. Biochem Biophys Res Commun 1998; 243 ; $480-484$

28) Liu X, Li P, Widlak P, et al. The $40-\mathrm{kDa}$ subunit of DNA fragmentation factor induces DNA fragmentation and chromatin condensation during apoptosis. Proc Natl Acad Sci USA 1998; 95: 8461-8466.

29) Ueki A, Kinugawa K, Hyodoh F, Kawakami $Y$, Sakaguchi H, Miyahara Y. The role of silica compounds in the autoimmune diseases accompanied by silicosis. Arch Complex Environ Studies 1996; 8: 53-56.

30) Kinugawa $K$, Ueki $A$, Yamaguchi $M$, et al. Activation of human CD4+CD45RA+ T cells by chrysotile asbestos in vitro. Cancer Lelt 1992; 66: 99-106.

31) Watanabe Y, Yamaguchi M, Kawakami Y, et al. Human CD $4+$ CD $45 \mathrm{RA}^{+}$lymphocytes can be stimulated by crocidolite, anthophyllite and amosite asbestos in vitro. Int J Oncol 1993; 2: 209-212.

32) Ueki A, Yamaguchi M, Ueki H, et al. Polyclonal human T-cell activation by silicate in vitro. Immunol 1994; 82: 332-335.

33) Ueki A, Nakashima $M$, Kishimoto T, Nakamura J, Kinugawa K, Sakaguchi $H$. Analysis of the expression of TCR V $\beta$ repertoires in patients with silicosis. J Occup Health 1996; 38: 67-70.

34) Aikoh T, Tomokuni A, Matsukii T, et al. Activationinduced cell death in human peripheral blood lymphocytes after stimulation with silicate in vitro. Int J Oncol 1998; 12: 1355-1359.

35) Otsuki T, Ichihara K, Tomokuni A, et al. Evaluation of cases with silicosis using the parameters related to Fasmediated apoptosis. Int J Mol Med. 1999; 4: 407-411.

36) Van Parijs L, Refaeli Y, Abbas AK, Baltimore D. Autoimmunity as a consequence of retrovirus-mediated expression of C-FLIP in lymphocytes. Immunity 1999; 11: 763-770. 